\title{
Thermal artefacts in two-photon solar cell experiments
}

\author{
Chris C. Phillips (1) ${ }^{1}$
}

Asahi et al. recently reported ${ }^{1}$ record increases $(\triangle E Q E)$ in the external quantum efficiency (EQE) of a heterojunction solar cell when it is illuminated with below-bandgap energy light. The EQE is the ratio of photocurrent electron flux to incident photon flux at zero bias. This 'two-step photon up-conversion' effect offers a way of breaking the $31 \%$ theoretical Shockley-Queisser solar cell efficiency limit ${ }^{2}$. However, the device transport is very temperature sensitive, and a $10 \mathrm{~K}$ temperature rise (see Fig. 3b, ref. ${ }^{1}$ ) increases the photocurrent by about $30 \%$ on its own ${ }^{1}$. The below-bandgap light is continuous wave (CW) and intense (about $360 \mathrm{~mW} \mathrm{~cm}^{-2}$ ). Here it is argued that the observed photocurrent increase is due to sample heating, not direct photoexcitation.

Bandgap light (wavelength, $\lambda$ of $\sim 780 \mathrm{~nm}$ ) creates photocarrier pairs in the GaAs which are separated by the depletion field. It is claimed that photoelectrons accumulate in a long-lived intermediate state ${ }^{3}$ at a $220 \mathrm{meV}$ high $\mathrm{Al}_{0.3} \mathrm{Ga}_{0.7} \mathrm{As} / \mathrm{GaAs}$ heterojunction barrier in the depletion zone, before being photoexcited over it by the below bandgap $(\lambda=1300 \mathrm{~nm})$ light and thus increasing the efficiency.

The best $(\triangle \mathrm{EQE}=30 \%)$ result came from a device measured in a solar simulator that also had a layer of InAs quantum dots (QDs) at the heterojunction ${ }^{1}$. However, a second measurement, using a $110 \mathrm{~mW}$ of CW $(\lambda=780 \mathrm{~nm})$ laser instead of the simulator, saw the short-circuit current $\left(J_{\mathrm{sc}}\right)$ increase from 6.6 to $7.2 \mathrm{~mA} \mathrm{~cm}^{-2}$, corresponding to a much lower $\triangle \mathrm{EQE}$ of $\sim 0.95 \%$. In other words, applying the $360 \mathrm{~mW} \mathrm{~cm}^{-2}$ of $\mathrm{CW}$ laser, with a wavelength of $\lambda=1300 \mathrm{~nm}$, increased the photocurrent by a fraction of about $8.5 \%$. This would correspond to a sample warming of $<3 \mathrm{~K}$.

The large (32 times) discrepancy between the two $\triangle \mathrm{EQE}$ measurements is not discussed in the paper ${ }^{1}$, so one can only speculate on its origins. The simulator illumination intensity was about $2 \mathrm{~mW} \mathrm{~cm}^{-2}$ spectrally integrated, corresponding to about $29 \mu \mathrm{W} \mathrm{cm}{ }^{-2}$ during the $350 \mathrm{~nm}$ wide EQE scan at $5 \mathrm{~nm}$ resolution (see Fig. 2a, b, ref. ${ }^{1}$ ). The $1300 \mathrm{~nm}$ laser was therefore between 180 and 12,000 times brighter than the simulator was designed to work with. This could have both heated the sample, and blinded the simulator's sensitive reference channel optical detectors with scattered laser light, causing it to over-report the $\triangle \mathrm{EQE}$. This would also explain why, somewhat surprisingly, a record $\triangle \mathrm{EQE}(\sim 10 \%)$ was also seen in the control sample (see Fig. 2d, ref. ${ }^{1}$ ) that had no QDs.

Concerning the photoexcitation over the barrier, the control sample result ( $\triangle \mathrm{EQE}$ approximately $10 \%$ ) (see Fig. $2 \mathrm{~d}$, ref. ${ }^{1}$ ) would have to be due to free-carrier absorption by the accumulated electrons. At these wavelengths, free-carrier absorption gives a cross section of about $6 \times 10^{-18} \mathrm{~cm}^{2}$ per electron ${ }^{4}$, and the fact that the QD and control samples gave comprable $\triangle \mathrm{EQE}$ results in the simulator would argue that the QD absorption cross section is similar. Taking the laser measurement for definiteness, the $110 \mathrm{~mW} \mathrm{~cm}^{-2}$ of bandgap light generates a photoelectron flux of about $4.1 \times 10^{15} \mathrm{~cm}^{-2} \mathrm{~s}^{-1}$. Dividing this by the photon flux in the $320 \mathrm{~mW} \mathrm{~cm}^{-2}$ beam $(\lambda$ of $1300 \mathrm{~nm})$ would imply that $1.95 \times 10^{-3}$ of the latter is involved in photoexciting electrons over the barrier. To get this absorption would need at least roughly $3.3 \times 10^{14} \mathrm{~cm}^{-2}$ electrons to be trapped at the barrier.

This electron density is about 330 times higher than the $n_{\mathrm{s}}$ of around $10^{12} \mathrm{~cm}^{-2}$ density of the QDs. It is also roughly 3300 times higher than the electron density ( $n_{\mathrm{s}}$ of around $1 \times$ $10^{11} \mathrm{~cm}^{-2}$ ) that would be enough to generate a field discontinuity, $\Delta E$ proportional to $e n_{\mathrm{s}} / \epsilon_{0} \epsilon_{\mathrm{r}}$, that is large enough to screen out ${ }^{5}$ the roughly $1.4 \times 10^{6} \mathrm{~V} \mathrm{~m}^{-1}$ depletion field that is needed to trap the electrons. This argues that the $\triangle \mathrm{EQE}$ effect cannot be explained by photoexcitation at the barrier.

Also reported was a roughly $2 \mathrm{mV}$ increase in the roughly $700 \mathrm{mV}$ open-circuit voltage $\left(V_{\mathrm{oc}}\right)$ when the $\lambda$ equals $1300 \mathrm{~nm}$ light was applied (Fig. 7 in ref. ${ }^{1}$ ). By comparing this with the $20 \mathrm{mV}$ approximate drop in $V_{\mathrm{oc}}$ seen when the device is warmed by $10 \mathrm{~K}$, it is argued that the light-induced rise in $V_{\text {oc }}$ must be non-thermal, because warming a normal $\mathrm{p}-\mathrm{n}$ junction increases the diode leakage current and therefore reduces $V_{\mathrm{oc}}$, whereas increasing the photocurrent will always increase $V_{\text {oc }}$. Firstly, these statements only apply to an ideal Shockley $\mathrm{p}-\mathrm{n}$ junction, with a drift-diffusion ${ }^{6}$ dark current and a constant photocurrent. Neither conditions apply to Asahi et al.'s heterostructure, where both photocurrent and the leakage currents increase strongly with temperature ${ }^{1}$. They will be influencing $V_{\mathrm{oc}}$ in opposite directions and in practice the direction of change of $V_{\mathrm{oc}}$ will depend in a complex way on bandgap changes and on experimental parameters, such as the bandgap

\footnotetext{
${ }^{1}$ Physics Department, Imperial College London, London SW7 2AZ, UK. Correspondence and requests for materials should be addressed to C.C.P. (email: chris.phillips@imperial.ac.uk)
} 
illumination intensity, so the observed sign of he change cannot be taken as evidence that it is caused by photoexcitation.

Secondly, there is the problem of experimental drift. The quoted $0.4 \mathrm{mV}$ accuracy on $V_{\mathrm{oc}}$ (Fig. $7 \mathrm{~b}$ error bars) translates into a $J_{\text {sc }}$ uncertainty of about $2.5 \times 10^{-5} \mathrm{~A} \mathrm{~cm}^{-2}$. This is only $1 / 270$ th of the $\sim 7 \mathrm{~mA} \mathrm{~cm}^{-2}$ photocurrent. Furthermore, the fact that Fig. 7a inset plot shows no data points or experimental noise implies a $V_{\mathrm{oc}}$ error that is less than the width of the lines in the graph. Measuring off the plot this is about $0.1 \mathrm{mV}$, i.e. about four times less than the error bars in Fig. $7 \mathrm{~b}$, so Fig. $7 \mathrm{a}, \mathrm{b}$ are not compatible.

To summarise, one has to conclude that Fig. 7 data could only be taken at face value if experimental parameters, such as the excition laser intensity and the effects of ambient light fluctuations were all controlled to better than one part in about 1000. This would be a formidable experimental achievement.

Finally, Asahi et al. point out that their $\triangle \mathrm{EQE}$ signals are "approximately two orders of magnitude greater than previously reported", and cite a number of related experiments. Many of these, and others in the literature, describe CW measurements that are also susceptible to these thermal artefacts.

$\triangle \mathrm{EQE}$ signals with a thermal origin have much slower response times than genuine electronic ones. They can be eliminated by intensity modulating the excitation laser(s) and checking that the $\triangle \mathrm{EQE}$ signal is independent of the modulation frequency ${ }^{5}$. The claims of Asahi et al. are incorrect becaue they have failed to demonstrate this. The purpose of this correspondence is to urge the experimental community to apply this simple experimental test in future work.

\section{Data availability}

The data are available from the author on request.

Received: 8 May 2018 Accepted: 22 October 2018

Published online: 27 February 2019

\section{References}

1. Asahi, S., Teranishi, H., Kusaki, K., Kaizu, T. \& Kita, T. Two-step photon up-conversion solar cells. Nat. Commun. 8, 14962 (2017).

2. Shockley, W. \& Queisser, H. J. Detailed balance limit of efficiency of PN junction solar cells'. J. Appl. Phys. 32, 510-519 (1961).

3. Yoshida, M., Ekins-Daukes, N. J., Farrell, D. J. \& Phillips, C. C. Photon ratchet intermediate band solar cells. Appl. Phys. Lett. 100, 263902 (2012).

4. Blakemore, J. F. Semiconducting and other major properties of gallium arsenide. J. Appl. Phys. 53, R123-R181 (1982).

5. Vaquero-Stainer, A. et al. Semiconductor nanostructure quantum ratchet for high efficiency solar cells. Comms. Physics 1, 7 (2018).

6. Sze, S. M. \& Ng, K. K. Physics of Semiconductor Devices (Wiley, New York, 2019).

\section{Author contributions}

C.C.P. performed the analysis and wrote the script.

\section{Additional information}

Competing interests: The authors declare no competing interests.

Reprints and permission information is available online at http://npg.nature.com/ reprintsandpermissions/

Publisher's note: Springer Nature remains neutral with regard to jurisdictional claims in published maps and institutional affiliations.

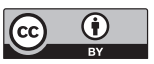

Open Access This article is licensed under a Creative Commons Attribution 4.0 International License, which permits use, sharing, adaptation, distribution and reproduction in any medium or format, as long as you give appropriate credit to the original author(s) and the source, provide a link to the Creative Commons license, and indicate if changes were made. The images or other third party material in this article are included in the article's Creative Commons license, unless indicated otherwise in a credit line to the material. If material is not included in the article's Creative Commons license and your intended use is not permitted by statutory regulation or exceeds the permitted use, you will need to obtain permission directly from the copyright holder. To view a copy of this license, visit http://creativecommons.org/ licenses/by/4.0/.

(C) The Author(s) 2019 